\title{
Evaluation of serum human epididymis protein 4 in patients with relapsing-remitting multiple sclerosis
}

\author{
Bożena Adamczyk ${ }^{1, A-D}$, Robert Partykaa $2, A, B$, Monika Adamczyk-Sowa ${ }^{1, E, F}$, \\ Krzysztof Wierzbicki ${ }^{1, A}$, Paweł Sowa ${ }^{3, A}$, Danuta Kokocińska ${ }^{2, A}$ \\ ${ }^{1}$ Department of Neurology in Zabrze, School of Medicine with the Division of Dentistry in Zabrze, Medical University of Silesia, Katowice, Poland \\ ${ }^{2}$ Department of Anesthesiology, Intensive Care and Emergency Medicine Ward, St. Barbara's Provincial Specialist Hospital in Sosnowiec, Medical University of Silesia, Katowice, \\ Poland \\ ${ }^{3}$ Department of Laryngology in Zabrze, School of Medicine with the Division of Dentistry in Zabrze, Medical University of Silesia, Katowice, Poland \\ A - research concept and design; $\mathrm{B}$ - collection and/or assembly of data; $\mathrm{C}$ - data analysis and interpretation; \\ $D$ - writing the article; $E$ - critical revision of the article; $F$ - final approval of the article
}

\section{Address for correspondence}

Bożena Adamczyk

E-mail: bozena.m.adamczyk@gmail.com

Funding sources

None declared

Conflict of interest

None declared

Received on November 17, 2019

Reviewed on March 9, 2020

Accepted on April 24, 2020

Published online on August 13, 2020

Cite as

Adamczyk B, Partyka R, Adamczyk-Sowa M, Wierzbicki K, Sowa P, Kokocińska D. Evaluation of serum human epididymis protein 4 in patients with relapsing-remitting multiple sclerosis. Adv Clin Exp Med. 2020;29(8):943-948. doi:10.17219/acem/121006

DOI

10.17219/acem/121006

Copyright

Copyright by Author(s)

This is an article distributed under the terms of the

Creative Commons Attribution 3.0 Unported (CC BY 3.0)

(https://creativecommons.org/licenses/by/3.0/)

\section{Abstract}

Background. So far, little is known about the properties of human epididymis protein 4 (HE4) in multiple sclerosis (MS). This type 4 glycoprotein belongs to a family of genes encoding proteins whose expression is associated with the process of spermatogenesis in the epididymis. The biological function of HE4 is not fully understood. Overexpression of HE4 has been found in several malignant tumors, particularly in ovarian cancer, as well as in mesothelioma, lung, endometrial, breast, and kidney cancers.

Objectives. To evaluate serum HE4 in patients with relapsing-remitting multiple sclerosis (RRMS) as compared to healthy controls.

Material and methods. Fifty patients with RRMS undergoing first-line immunomodulatory treatment were enrolled in the prospective study. We analyzed correlations between serum HE4 levels and gender, age, disease duration, the Expanded Disability Status Scale (EDSS), annualized relapse rate (ARR), and magnetic resonance imaging (MRI) lesions.

Results. The patients from the study group had higher concentrations of HE4 than the subjects from the control group. Patients with EDSS $>2$ had significantly higher concentrations of HE4. Positive correlations were found between HE4 concentrations and age as well as between HE4 concentrations and disease duration. No significant correlations were found between HE4 concentrations and EDSS or between HE4 concentrations and ARR.

Conclusions. The results of the study indicate a novel aspect of the HE4 protein in the pathomechanisms of MS.

Key words: multiple sclerosis, autoimmune diseases, biomarker, human epididymis protein 4, relapsingremitting multiple sclerosis 


\section{Introduction}

Serum human epididymis protein 4 (HE4) antigen was discovered by Kirchhoff et al. in 1991. ${ }^{1}$ Its usefulness as a potential tumor marker of ovarian cancer was described by Schummer et al. in $1999^{2}$ and confirmed by Hellström et al. in $2003 .{ }^{3}$ This type 4 glycoprotein belongs to a family of gene-encoding proteins containing whey-acidic-protein (WAP) motifs, whose expression is associated with the process of spermatogenesis in the epididymis. ${ }^{4}$ The HE4 is a protein from the group of small thermostable molecules involved in inhibiting the activity of proteases. Since it is released into the circulation, it is possible to determine its concentration in blood serum.

The biological function of this protein is not fully understood. It is known that HE4 promotes tumor growth and the migration and adhesion of ovarian cancer cells. Overexpression of this protein has been found in several malignant tumors, particularly in ovarian cancer, as well as in mesothelioma, lung, endometrial, breast, and kidney cancers. ${ }^{5,6}$ Compared with cancer antigen 125 (CA-125), its increase in benign lesions and non-neoplastic diseases is much less common in premenopausal women ( $8 \%$ vs $29 \%)^{7}$

Reviewing the literature on HE4, it can be seen that HE4 has been analyzed from many perspectives. The most recent reports have assessed its usefulness as a marker in ovarian cancer and pulmonary tuberculosis, or investigated the relationship between HE4 and renal function and diabetic kidney disease in patients with type 2 diabetes mellitus. ${ }^{8}$ Furthermore, Gasiorowska et al. analyzed the level of HE4 in blood serum in relation to smoking and age; they suggested that permanent inflammation caused by smoking may induce an increase in HE4. ${ }^{9}$ Other authors have indicted an association between HE4 and an increase in myocardial injury expressed by N-terminal pro-b-type natriuretic peptide (NT-proBNP) and troponin T. ${ }^{10}$

It is known that autoimmune and chronic inflammatory processes are involved in the pathomechanism of multiple sclerosis (MS). However, it seems that oxidative stress (OS) is also crucial to cancer development, and recent studies have demonstrated that some drugs effective in MS (e.g., fingoli$\bmod (\mathrm{FG})$ ) may also be helpful in cancer treatment. ${ }^{11}$ It seems that in light of this, the assessment of HE4 in MS may provide new information, particularly due to the fact that diagnostic and prognostic markers are constantly being sought in MS. ${ }^{12}$

We have found no reports that analyzed HE4 in patients with MS. The aim of this study was to evaluate serum HE4 in MS patients compared to a control group.

\section{Material and methods}

We assessed serum HE4 in MS patients in relation to gender, age, disease duration, degree of disability in the Expanded Disability Status Scale (EDSS), annualized relapse rate (ARR), and MRI Gd + lesions.
The study involved 50 patients diagnosed with relapsingremitting multiple sclerosis (RRMS) according to the 2010 McDonald criteria, who were treated mainly with firstline immunomodulatory therapy. The study also involved 26 healthy volunteers as a control group. Among the patients, $54.28 \%$ (19) were being treated with interferon $\beta-1 \mathrm{a}$ (IFN $\beta$-1a) (30 ug intramuscularly (i.m.) weekly or 44 ug s.c. 3 times weekly); $31.43 \%$ (11) with IFN $\beta-1 b$ (250 ug every second day s.c.); $11.43 \%$ (4) with glatiramer acetate $(20 \mathrm{mg} /$ daily s.c.); and $2.86 \%$ (1) with fingolimod (FG) ( $0.5 \mathrm{mg} /$ daily p.o.). Only FG is approved as second-line therapy.

The inclusion criteria for the study group were as follows: age $\geq 18$ years, RRMS diagnosed according to the 2010 McDonald criteria, no relapse, and written informed consent for participation in the study. The exclusion criteria were refusal to give written informed consent to participate in the study and confirmed cancer or other severe disease.

The inclusion criteria for the control group were as follows: generally healthy individuals (treatment of hypertension was not a contraindication) and written informed consent to participate; the exclusion criteria for the controls were the same as for the patient group.

A $10 \mathrm{~mL}$ venous blood sample was obtained from all participants, taken a minimum of $4 \mathrm{~h}$ after the MS patients were administered their medications. After centrifugation of the blood samples, the obtained serum was frozen at $-20^{\circ} \mathrm{C}$. In all the samples, $\mathrm{HE} 4$ concentration was determined using chemiluminescence commercial kits (Abbott Laboratories, Abbott Park, USA). Concentrations below $22 \mathrm{pg} / \mathrm{mL}$ were considered normal.

Demographic data, disease duration, clinical disease onset, the clinical form of MS, the type of treatment, the degree of disability in the EDSS, ARR and lesions on magnetic resonance imaging (MRI) were obtained from medical databases from Department of Neurology at the Medical University of Silesia (Zabrze, Poland).

STATISTICA v. 9.1 software (StatSoft Inc, Tulsa, USA) was used for the statistical analysis. P-value $<0.05$ was considered statistically significant. The normality of the distribution was checked using the Shapiro-Wilk test. Demographic characteristics and all the results were expressed as the number (n), the arithmetic mean, standard deviation (SD), and percentage (\%). The homogeneity of continuous variables between the groups was analyzed using the parametric analysis of variance (ANOVA) test (for normally distributed variables) or the non-parametric Kruskal-Wallis ANOVA (for variables whose distribution was not normal). Post hoc analysis using Tukey's test with the Bonferroni correction was conducted in the case of statistically significant differences. Student's t-test and the non-parametric Mann-Whitney U test were used to compare the 2 groups. The relationships between the attributes were evaluated using the nonlinear Spearman correlation. The results were stored in a database prepared specifically for this purpose in Microsoft Excel (Microsoft Corp., Redmond, USA). 


\section{Results}

Table 1 presents the characteristics of the study groups. The mean age of the MS group was $38.66 \pm 8.24$ years, and of the control group $37.69 \pm 8.64$ years. The number of female patients was higher than the number of males (Table 1).

Table 2 shows an analysis of the study group considering the clinical and radiological indicators of disease activity, such as disease duration, EDSS, ARR, and T2 MRI lesions. The patients were mainly treated with IFN $\beta$. The mean disease duration in the MS group was $8.91 \pm 5.52$ years.

Patients from the MS group had higher concentrations of HE4 than the subjects from the control group. A post hoc analysis was conducted for women and men in both groups. No differences were found between male and

Table 1. General characteristics of the groups

\begin{tabular}{|l|c|c|c|}
\hline \multicolumn{1}{|c|}{ Group } & MS group & Control group & p-value \\
\hline $\mathrm{n}$ & 35 & 26 & - \\
\hline Age [years] & $38.66 \pm 8.24$ & $37.69 \pm 8.64$ & 0.7 \\
\hline Gender (\% of females) & 74.28 & 61.54 & - \\
\hline
\end{tabular}

MS group - multiple sclerosis group; statistical significance at $p<0.05$.

Table 2. Clinical characteristics of the study group

\begin{tabular}{|c|c|}
\hline Group & MS group \\
\hline $\begin{array}{l}\text { Type of treatment in I-line: } \\
\text { IFNß 1a (\%) } \\
\text { IFNß 1b (\%) } \\
\text { glatiramer acetate (\%) }\end{array}$ & $\begin{array}{c}54.28(19) \\
31.43(11) \\
11.43(4)\end{array}$ \\
\hline $\begin{array}{l}\text { Il line treatment: } \\
\text { fingolimod (\%) }\end{array}$ & $2.86(1)$ \\
\hline Disease duration [years] & $8.91 \pm 5.52$ \\
\hline EDSS (score) & $2.24 \pm 1.13$ \\
\hline T2 MRI lesions (N) & $19.16 \pm 2.80$ \\
\hline
\end{tabular}

MS group - multiple sclerosis group; IFN $\beta$ - interferon beta;

EDSS - Expanded Disability Status Scale; ARR - annualized relapse rate.

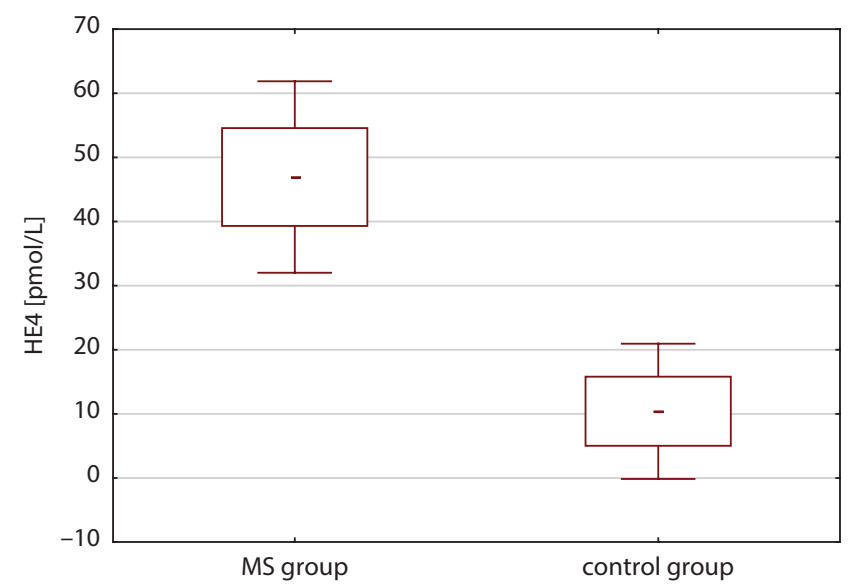

female MS patients' concentrations of HE4. The women and men with MS had higher concentrations of HE4 than the women and men in the control group (Fig. 1).

A comparison was made between patients with and without a relapse within the last year, and the analysis did not show any differences in the serum HE4 concentrations of these patients. However, patients with EDSS $>2$ had significantly higher concentrations of HE4 than those with lower EDSS scores (Table 3).

No significant correlations were found for gadoliniumenhancing $(\mathrm{Gd}+)$ lesions or ARR. A moderate negative correlation was revealed between Gd+ and HE4. Among the women with MS, a positive correlation was found between HE4 and EDSS scores. No significant correlations were noted for men with MS (Table 4).

\section{Discussion}

Multiple sclerosis is a biphasic disease.$^{13}$ Initially, neuroinflammation is prevalent, ${ }^{14}$ which induces OS in the nervous tissue, leading to impaired oxidative/antioxidant balance, ${ }^{12}$ a loss of blood-brain barrier integrity, ${ }^{15-17}$ demyelination, and neurodegeneration. ${ }^{12}$ The ultimate mechanism for the development of MS is not known. Due to the development of novel methods of MS treatment, the timing of a switch to more aggressive treatment is of great importance. An ongoing search for new markers is underway, with the aim of helping to assess the prognosis. In the future, HE4 could be used as a new indicator of disease progression, as it is in ovarian cancer, endometrial cancer, renal failure, ${ }^{18-20}$ and other diseases.

The WAP four-disulfide core domain protein 2 gene (WFDC2) encodes HE4. WFDC2 gene expression has been discovered in the epididymis, vas deferens, the epithelium of the female genital tract, the breast, respiratory epithelium, intestines, salivary glands, and distal renal tubules. ${ }^{6,21}$ Studies of the expression of the HE4 protein in the central nervous system (CNS) have not yet been

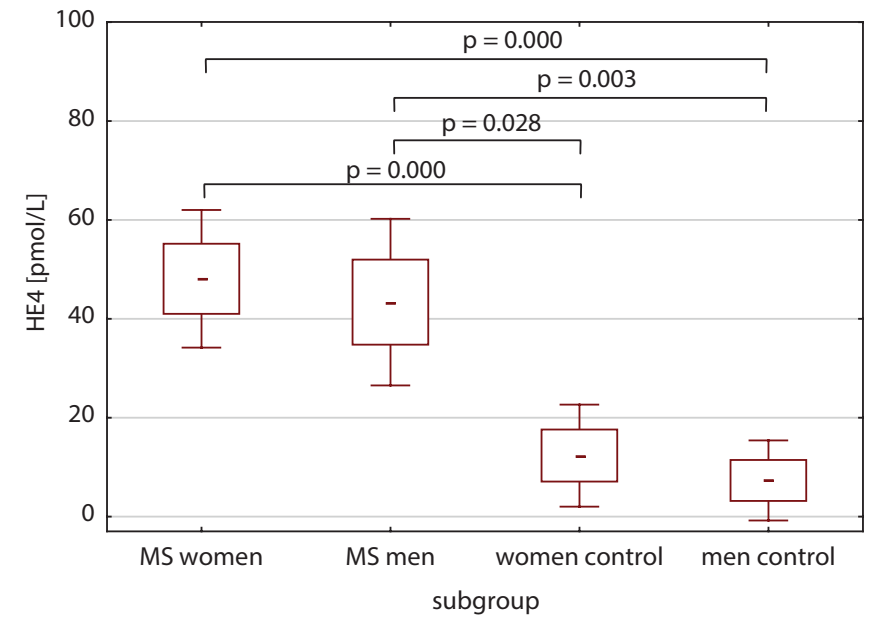

Fig. 1. A comparison of the study group and control group in terms of HE4 and an analysis in subgroups by gender (means and SD) 
conducted. It is difficult to assess whether the observed increase in HE4 in MS patients is a result of increased HE4 expression outside the CNS or other mechanisms, including the involvement of nervous tissue. In the future, studies should aim at assessing the effect of the HE4 protein on the integrity of the blood-brain barrier. The aim of our paper was to provide a preliminary assessment of the concentrations of HE4 in MS patients. Due to the fact that no studies assessing HE4 among MS patients have been conducted, the conclusions from our study have to be treated with caution.

Significantly higher concentrations of HE4 were observed in the patients with MS compared to the controls. Patients with a worse course of the disease (EDSS > 2) had higher HE4 concentrations than patients with EDSS $\leq 2$. Those with EDSS > 2 did not differ in terms of age from those with lower EDSS scores (data not shown).

The concentration of HE4 did not increase with the age or disease duration. The lack of age dependence among healthy individuals may be due to their younger age and smaller SD, with insufficient numbers to reach statistical significance. It appears that HE4 levels may be age-related, because HE4 is an essential marker of ovarian and endometrial cancer in premenopausal women ${ }^{22}$ and pregnant women. ${ }^{23}$

Our study did not find any differences between male and female MS patients' HE4 levels. The group of men was smaller, and a study with a larger cohort is necessary. Women are more often affected by MS, which may result from hormonal predispositions ${ }^{24,25}$ and various additional factors. One study revealed that the concentrations of HE4 in women with ovarian cancer were generally higher than those in our patients with MS. ${ }^{18}$ The highest

Table 3. Analysis of selected factors of disease activity in the study group in relation to HE4

\begin{tabular}{|l|c|c|c|}
\multicolumn{1}{|c|}{ Group } & With relapse & With no relapse & p-value \\
\hline N & 9 & 26 & - \\
\hline HE4 [pmol/L] & $47.44 \pm 7.65$ & $46.15 \pm 7.75$ & 0.66 \\
\hline \multicolumn{1}{|c|}{ Group } & EDSS $\leq 2$ & EDSS $>2$ & p-value \\
\hline N & 21 & 12 & - \\
\hline HE4 [pmol/L] & $44.66 \pm 6.13$ & $50.96 \pm 8.54$ & 0.019 \\
\hline
\end{tabular}

HE4 - human epididymis protein 4; EDSS - Expanded Disability Status Scale. concentrations were found in epithelial ovarian cancer, which may suggest the involvement of epithelial tissue in HE4 production. ${ }^{18,26}$

The involvement of hormonal disorders may play a key role in the increase in HE4 among women with MS compared to healthy women. However, this conclusion should be treated with caution. No studies have been performed to assess the relationship between HE4 and hormonal disorders in women with MS. It is known that the HE4 protein causes the resistance of ovarian cancer cells to anti-estrogens (e.g., tamoxifen); it has been found that HE4 interacts with estrogen receptor $\alpha(E R-\alpha)$, and the overexpression of $\mathrm{HE} 4$ reduces the expression of ER- $\alpha$ in ovarian cancer cells. $^{27}$

Another analysis of the dependence of HE4 on gender indicated that the protein has been recognized as one of the most important prognostic markers not only in ovarian cancer but also in endometrial cancer. ${ }^{18}$ Higher concentrations of the protein have been found among women with atypical endometrial hyperplasia compared to women without this condition. ${ }^{19}$ Studies on HE4 indicate that it has multi-directional effects in men as well. The protein plays a key role in fertilization, especially in sperm maturation, motility and capacity. ${ }^{28}$

In our study, HE4 concentration was increased in women with EDSS $\geq 2$. This suggests that EDSS and HE4 concentration can be prognostic factors, but further studies are needed to confirm this.

Among the limitations of our study are the small sample size and the lack of complete homogeneity between the groups in terms of age and gender. However, the results suggest that the protein could be involved in the pathomechanism of MS in both women and men. In the literature, HE4 is most often discussed in terms of ovarian cancer, but it should be borne in mind that it also plays a significant role in spermatogenesis. ${ }^{4}$ Currently, OS is postulated in spermatogenic disorders ${ }^{29}$ and in the development of tumors and MS. An analysis of the relationship between the functions of HE4 and OS could be useful in further research.

The role of this unique protein is increasingly being discussed in relation to many diseases. The HE4 is a useful marker for differentiating between lupus nephritis and systemic lupus erythematosus. ${ }^{30}$ A study has shown that the participation of HE4 in autoimmune diseases may be

Table 4. Analysis of the most important correlations for the MS group in relation to gender

\begin{tabular}{|c|c|c|c|c|c|c|}
\hline Parameter & Age [years] & Disease duration [years] & ARR & EDSS & Gd+ MRI lesions (N) & Group \\
\hline HE4 & NS & NS & NS & NS & $\begin{array}{c}R=-0.390 \\
P=0.024\end{array}$ & MS group \\
\hline HE4 & NS & NS & NS & $\begin{array}{l}R=0.56 \\
P=0.003\end{array}$ & NS & women with MS \\
\hline HE4 & NS & NS & NS & NS & NS & men with MS \\
\hline
\end{tabular}

HE4 - human epididymis protein 4; MS group - multiple sclerosis group; EDSS - Expanded Disability Status Scale; ARR - annualized relapse rate; $\mathrm{NA}$ - non-applicable; $\mathrm{R}$ - Spearman linear correlation coefficient. 
significant: The protein modified the functions of the immune system, for instance, with rendering ovarian tumors undetectable by immune surveillance. ${ }^{31}$

Explaining the role of HE4 and the immune system in the formation of cancer seems to be essential. It is known that many molecules such as programmed cell death protein 1 (PD-1), cytotoxic T-lymphocyte-associated protein 4 (CTLA4), and T-cell immunoglobulin help tumor cells escape immune targeting and elimination. ${ }^{32}$ Nivolumab, a monoclonal antibody that binds to PD-1, prevents tumor spread. ${ }^{33}$ Shen et al. showed the possibility of using a highaffinity monoclonal antibody against HE4. ${ }^{34}$ Monoclonal antibodies are also widely used in autoimmune diseases. The role of HE4 could be explained by searching for similarities between the development of MS and cancer. Many of the same factors may have different key functions in the body depending on the type of activation. This mechanism is common among tumors, e.g., the action of dual specificity phosphatase 6 (DUSP6) may depend on the type and stage of cancer and may enhance or block tumor growth. ${ }^{32}$

The participation of HE4 in the development of ovarian cancer is better understood. It is known that an increase in HE4 is associated with a worse prognosis because this protein induces tumor growth, metastasis, proliferation, anti-estrogen resistance, and chemoresistance. ${ }^{32}$ James et al. explained the effect of HE4 on the development of ovarian cancer: In their study, DUSP6 was found to be upregulated by recombinant human HE4 treatment in $\mathrm{CD}^{+} \mathrm{T}$ and $\mathrm{CD}^{+} 6^{+} \mathrm{NK}$ cell subsets of human peripheral blood mononuclear cells, which enhanced tumorigenesis in ovarian cancer. ${ }^{32}$

One study revealed that HE4 could be a significant biomarker of decreased kidney function and renal fibrosis in kidney transplant recipients. Furthermore, serum HE4 concentrations increased with disease severity, the severity of fibrosis and HE4 tissue expression in renal biopsies. ${ }^{20}$ In the future, post-mortem examinations of MS patients' brain tissue should be conducted to determine the concentration of HE4.

Wang et al. suggested that HE4 could be a potential biomarker of kidney damage in acute and chronic renal dysfunction. ${ }^{35}$ Other authors did not find any association between HE4 and liver fibrosis or cirrhosis. ${ }^{36}$

Another limitation of our study was that HE4 concentrations were evaluated only in the serum, which may not reflect the concentrations in the CNS. Additionally, we did not perform a comparative analysis of patients with more advanced forms of MS (i.e., primary progressive MS or secondary progressive MS). However, as already mentioned, no other studies have been conducted assessing the importance of HE4 among women and men with MS. Our study is innovative since it aims to provide an initial analysis of the MS population relative to HE4.

In the future, HE4 could be used as a new indicator of disease progression in MS as in other diseases.
The mechanism responsible for the increase in HE4 protein in MS patients remains unknown. Female hormones could be involved in the concentration of the protein, as in ovarian cancer. Studies on HE4 have also indicated its multi-directional effect in men. Currently, OS is postulated in spermatogenesis disorders; an analysis of the relationship between the functions of HE4 and OS could probably be useful in further research.

\section{Conclusions}

It is possible that among patients with more severe MS, especially in women, HE4 may be a prognostic factor. Further studies on the importance of the HE4 protein in MS are warranted. This protein could be involved in the pathomechanism of MS and could become a novel target of treatment.

\section{ORCID iDs}

Bożena Adamczyk (D) https://orcid.org/0000-0003-1641-5350 Robert Partyka (D) https://orcid.org/0000-0002-0136-2914 Monika Adamczyk-Sowa (D) https://orcid.org/0000-0002-6894-9891 Krzysztof Wierzbicki (D) https://orcid.org/0000-0001-5019-581X Paweł Sowa (D) https://orcid.org/0000-0001-6179-2572

Danuta Kokocińska (D) https://orcid.org/0000-0002-0453-7900

\section{References}

1. Kirchhoff $C$, Habben I, Ivell R, Krull N. A major human epididymisspecific cDNA encodes a protein with sequence homology to extracellular proteinase inhibitors. Biol Reprod. 1991;45(2):350-357.

2. Schummer M, Ng WV, Bumgarner RE, et al. Comparative hybridization of an array of 21,500 ovarian CDNAs for the discovery of genes overexpressed in ovarian carcinomas. Gene. 1999;238(2):375-385.

3. Hellström I, Raycraft J, Hayden-Ledbetter M, et al. The HE4 (WFDC2) protein is a biomarker for ovarian carcinoma. Cancer Res. 2003;63(13): 3695-3700.

4. Jia LT, Zhang YC, Li J, Tian Y, Li JF. The role of human epididymis protein 4 in the diagnosis of epithelial ovarian cancer. Clinical Trans/ Oncol. 2016;18(3):233-239.

5. Li J, Chen H, Mariani A, et al. HE4 (WFDC2) promotes tumor growth in endometrial cancer cell lines. Int J Mol Sci. 2013;14(3):6026-6043.

6. Galgano MT, Hampton GM, Frierson HF Jr. Comprehensive analysis of HE4 expression in normal and malignant human tissues. Mod Pathol. 2006;19(6):847-853.

7. Moore RG, Miller MC, Steinhoff MM, et al. Serum HE4 levels are less frequently elevated than CA125 in women with benign gynecologic disorders. Am J Obstet Gynecol. 2012;206(4):351.e1-e8.

8. Zhang $M$, Zhao B, Xie J, Liang $Y$, Yang Z. Serum human epididymis protein 4 is associated with renal function and diabetic kidney disease in patients with type 2 diabetes mellitus. Biomed Res Int. 2019;2019: 4831459.

9. GasiorowskaE,KluzT,LipskiD, WarcholW,TykarskiA, Nowak-MarkwitzE. Human epididymis protein 4 (HE4) reference limits in Polish population of healthy women, pregnant women, and women with benign ovarian tumors. Dis Markers. 2019;2019:3890906.

10. Piek A, Meijers WC, Schroten NF, Gansevoort RT, de Boer RA, Sillje HH. HE4 serum levels are associated with heart failure severity in patients with chronic heart failure. J Card Fail. 2017;23(1):12-19.

11. Takasaki T, Hagihara K, Satoh R, Sugiura R. More than just an immunosuppressant: The emerging role of FTY720 as a novel inducer of ROS and apoptosis. Oxid Med Cell Longev. 2018;2018:4397159.

12. Adamczyk B, Adamczyk-Sowa M. New insights into the role of oxidative stress mechanisms in the pathophysiology and treatment of multiple sclerosis. Oxid Med Cell Longev. 2016;2016:1973834. 
13. Fiorini A, Koudriavtseva T, Bucaj E, et al. Involvement of oxidative stress in occurrence of relapses in multiple sclerosis: The spectrum of oxidatively modified serum proteins detected by proteomics and redox proteomics analysis. PloS One. 2013;8(6):e65184.

14. Mossakowski AA, Pohlan J, Bremer D, et al. Tracking CNS and systemic sources of oxidative stress during the course of chronic neuroinflammation. Acta Neuropathol. 2015;130(6):799-814.

15. van Horssen J, Witte ME, Schreibelt G, de Vries HE. Radical changes in multiple sclerosis pathogenesis. Biochim Biophys Acta. 2011;1812(2): 141-150.

16. Witherick J, Wilkins A, Scolding N, Kemp K. Mechanisms of oxidative damage in multiple sclerosis and a cell therapy approach to treatment. Autoimmune Dis. 2010;2011:164608.

17. Dringen R. Oxidative and antioxidative potential of brain microglial cells. Antioxid Redox Signal. 2005;7(9-10):1223-1233.

18. Brenk A, Bodzek P, Balis M, Barbachowska A, Janosz I, Olejek A. Usefulness of HE4 protein in differentiation of pelvic masses in woman. Prz Menopauzalny. 2019;18(1):27-32.

19. Li X, Gao Y, Tan M, et al. Expression of HE4 in endometrial cancer and its clinical significance. Biomed Res Int. 2015;2015:437468 [Erratum in: Corrigendum to "Expression of HE4 in endometrial cancer and its clinical significance". Li X, Gao Y, Tan M, Zhuang H, et al. Biomed Res Int. 2018;2018:6795629. doi:10.1155/2018/6795629].

20. Luo J, Wang F, Wan J, et al. Serum human epididymis secretory protein 4 as a potential biomarker of renal fibrosis in kidney transplantation recipients. Clin Chim Acta. 2018;483:216-221.

21. Nowak M, Janas L, Stachowiak G, Stetkiewicz T, Wilczynski JR. Current clinical application of serum biomarkers to detect ovarian cancer. Prz Menopauzalny. 2015;14(4):254-259.

22. Dong C, Liu P, Li C. Value of HE4 combined with cancer antigen 125 in the diagnosis of endometrial cancer. Pak J Med Sci. 2017;33(4): 1013-1017.

23. Uslu B, Dogan S, Ozdem S, Simsek T. Serum concentrations of HE4 and Ca125 in uncomplicated pregnancies: A longitudinal study. J Obstet Gynaecol. 2020; 40(1):70-76.

24. Avila M, Bansal A, Culberson J, Peiris AN. The role of sex hormones in multiple sclerosis. Eur Neurol. 2018;80(1-2):93-99.
25. Neto LO, Gromisch ES, Sloan J, Tyry T, Foley FW. Sex differences in predictors of illness intrusiveness in persons with multiple sclerosis. Qual Life Res. 2019;28(2):389-397.

26. Dewan R, Dewan A, Jindal M, Bhardawaj M. Diagnostic performance of serum human epididymis protein 4 (HE4) for prediction of malignancy in ovarian masses. Asian Pac J Cancer Prev. 2019;20(4):1103-1108.

27. Lokich E, Singh RK, Han A, et al. HE4 expression is associated with hormonal elements and mediated by importin-dependent nuclear translocation. Sci Rep. 2014;4:5500.

28. Kant K, Tomar AK, Sharma P, Kundu B, Singh S, Yadav S. Human epididymis protein 4 quantification and interaction network analysis in seminal plasma. Protein Pept Lett. 2019;26(6):458-465.

29. Nowicka-Bauer K, Lepczynski A, Ozgo M, et al. Sperm mitochondrial dysfunction and oxidative stress as possible reasons for isolated asthenozoospermia. J Physiol Pharmacol. 2018;69(3). doi:10.26402/ jpp.2018.3.05

30. Ren Y, Xie J, Lin F, et al. Serum human epididymis protein 4 is a predictor for developing nephritis in patients with systemic lupus erythematosus: A prospective cohort study. Int Immunopharmacol. 2018;60: 189-193.

31. James NE, Cantillo E, Oliver MT, et al. HE4 suppresses the expression of osteopontin in mononuclear cells and compromises their cytotoxicity against ovarian cancer cells. Clin Exp Immunol. 2018;193(3): 327-340.

32. James $\mathrm{NE}$, Oliver MT, Ribeiro JR, et al. Human epididymis secretory protein 4 (HE4) compromises cytotoxic mononuclear cells via inducing dual specificity phosphatase 6. Front Pharmacol. 2019;10:216.

33. Volpe VO, Klufas DM, Hegde U, Grant-Kels JM. The new paradigm of systemic therapies for metastatic melanoma. J Am Acad Dermatol. 2017;77(2):356-368.

34. Shen $Y$, Wang $Y$, Jiang $X$, et al. Preparation and characterization of a highaffinity monoclonal antibody against human epididymis protein-4. Protein Expr Purif. 2018;141:44-51.

35. Wang L, Sun Y, Cai X, Fu G. The diagnostic value of human epididymis protein 4 as a novel biomarker in patients with renal dysfunction. Int Urol Nephrol. 2018;50(11):2043-2048.

36. Zhang M, Yuan L, Yao F, et al. Human epididymis protein 4 concentration is not associated with liver fibrosis and cirrhosis in a case control study. Clin Chim Acta. 2018;484:213-217. 